\title{
A Percepção de Gêneros Textuais/Discursivos do Professor de Língua Materna
}

The perception of textual and discursive genres by the first language teacher

\author{
Alessandra Baldo*
}

INTRODUÇÃo

Enquanto parece indiscutível que há um número significativo de produções científicas relativas a gêneros textuais/discursivos, ${ }^{1}$ especialmente na interface com a linguagem e a educação, também parece razoável afirmar que essas produções têm se concentrado em três grandes áreas, ou seja, propostas de ensino da língua portuguesa a partir da concepção de gênero; abordagem de gênero textual/discursivo em livros didáticos; análise de gêneros variados.

Percebe-se, com isso, que a percepção de gênero textual/discursivo do professor de língua portuguesa não tem sido o foco desses estudos, salvo casos isolados (por exemplo, ROJO, 2003a). Apesar de muitos trabalhos afirmarem que o ensino da língua portuguesa que visse gêneros textuais/discursivos seria mais eficaz, isso naturalmente apenas poderá ocorrer se o professor possuir um conhecimento teórico suficiente sobre a questão. Além disso, ainda que muitas análises tenham mostrado que a abordagem de gêneros feita nos livros didáticos é insuficiente, isso não implica necessariamente que a do professor também o seja. Como assinala BIASI-RODRIespaço, não será tratada aqui. A esse respeito, ver Rojo (2003). 
GUES (2002) em artigo no qual investiga o tratamento dispensado a gêneros textuais/discursivos em três coleções e conclui que nenhuma delas contempla seu reconhecimento, o livro didático não tem o compromisso de propor cada tarefa passo a passo, cabendo ao professor o embasamento teórico para "lidar com os novos conceitos e construir uma nova prática que atenda à atual demanda das interações comunicativas."(p. 58)

Considerando esse quadro, o objetivo deste artigo é mostrar os resultados de um estudo elaborado com o objetivo primeiro de verificar a concepção de gênero textual/discursivo do professor de língua portuguesa de ensino fundamental e/ou médio para, daí, poder analisar em que medida essa concepção está em sintonia com a advinda da noção teórica de gênero discursivo da tradição bakhtiniana, selecionada pelos Parâmetros Curriculares Nacionais (PCNs) para o Ensino da Língua Portuguesa. Os dados foram obtidos a partir de questionários aplicados a 26 professores inscritos em cursos de especialização na Grande Porto Alegre (RS). A partir dessa proposta, delimitamos quatro objetivos específicos: (1) determinar se os professores de língua portuguesa têm consciência de que a noção de gênero textual/discursivo deve ser ensinada em seu componente curricular; (2) verificar a noção de gênero textual/discursivo dos professores de língua portuguesa; (3) identificar o grau de proximidade/afastamento entre a noção de gênero delineada nos PCNs para a língua portuguesa e a noção de gênero do professor de língua materna; (4) examinar a abordagem utilizada por esse professor para ensinar gênero.

$\mathrm{O}$ estudo foi dividido em três partes. Na primeira, procedemos a uma retomada da abordagem da noção de gênero discursivo de Bakhtin, devido tanto à importância de sua teoria nos estudos recentes sobre gênero em lingüística aplicada, como a sua influência na definição de gênero presente nos PCNs, e revisamos a literatura sobre a abordagem do gênero na escola e sobre a importância do estudo de gênero. Na segunda parte apresentamos o levantamento e a análise das informações obtidas por meio dos questionários aplicados aos professores, e na última buscamos resgatar nossos objetivos iniciais respondendo às questões colocadas pelo estudo.

\section{GÊNEROS DISCURSIVOS EM BAKHTIN}

Bakhtin (1992) chega à definição de gênero apresentada nos PCNsi.e., tipos relativamente estáveis de enunciados disponíveis na cultura partindo da verificação de que todas as esferas da atividade humana estão relacionadas com a utilização da língua. Essa utilização se dá em forma de 
enunciados, os quais, por sua vez, "refletem as condições específicas e as finalidades de cada uma dessas esferas" (p. 279) tanto por seu conteúdo quanto por seu estilo verbal como por sua construção composicional. Assim, o tema, o estilo e a construção composicional formam um tipo característico de enunciado dentro de um dado espaço de comunicação, e é por isso que tipos estáveis de enunciado caracterizam gêneros do discurso.

Antes de preocupar-se em classificar os diferentes gêneros discursivos, Bakhtin chama a atenção para a sua diversidade: sendo utilizados em todas as esferas da atividade humana, eles vão se diferenciando e ampliando na medida em que estas se desenvolvem ou se ampliam. No seu entender, ao invés de se privilegiar o estudo de apenas alguns gêneros (literários, retóricos, do discurso cotidiano), o mais importante é levar em conta a diferença fundamental entre gêneros primários, ou simples, e secundários, ou complexos. Como o próprio nome diz, os gêneros primários se constituiriam em circunstâncias de uma comunicação verbal espontânea (a réplica do diálogo cotidiano, a carta), enquanto os secundários apareceriam "em circunstâncias de uma comunicação cultural mais complexa e relativamente mais evoluída, principalmente escrita: artística, científica, sociopolítica" (p. 281). Para Bakhtin, a distinção entre estes dois conjuntos de gêneros não deve ser menosprezada porque

ignorar a natureza do enunciados e as particularidades do gênero que assinalam a variedade do discurso em qualquer área do estudo lingüístico leva ao formalismo e à abstração, desvirtua a historicidade do estudo, enfraquece o vínculo existente entre a língua e a vida. (BAKHTIN, 1992, p. 283).

Como se pode ver, um conceito crucial em Bakhtin é o de enunciado, entendido como a unidade de comunicação utilizada pelos sujeitos. Ao criticar o papel passivo atribuído às funções de ouvinte e receptor pelas teorias lingüísticas, o autor argumenta que o ouvinte, ao receber e compreender a significação de um discurso, tem uma atitude responsiva ativa, a qual é, na verdade, esperada pelo locutor. Para o autor, essa compreensão responsiva, mesmo que não se realize de forma imediata ou por um ato lingüístico, constitui a fase preparatória para uma resposta. Além disso, complementa, o próprio locutor é um respondente na medida em que seu enunciado pressupõe a existência de enunciados anteriores, vinculados ao seu próprio enunciado de algum modo e, supostamente, conhecidos de seu ouvinte. A partir disso, pode-se entender melhor por que o enunciado bakhtiniano está tão diretamente relacionado com essa noção de atitude responsiva. Diferentemente de noções correntes em lingüística, o enunciado en- 
quanto unidade real de comunicação verbal é caracterizado por Bakhtin (i) por suas fronteiras - determinadas pela alternância dos sujeitos falantes -e (ii) seu acabamento. Esse acabamento pode ser medido por critérios específicos, o mais importante sendo a possibilidade de adotar uma atitude responsiva para com ele, e é determinado por três fatores: o tratamento exaustivo do objeto do sentido, o intuito, o querer-dizer do locutor e as formas típicas de estruturação do gênero do acabamento.

Com relação às fronteiras do enunciado, vale ressaltar que a alternância dos sujeitos falantes se aplica igualmente a gêneros tão diversos como o diálogo cotidiano e o romance. Embora no último a alternância não seja direta (o interlocutor não está presente) nem imediata (a leitura de um romance demanda um determinado tempo), ela acontece assim que a leitura é concluída. De acordo com o autor, "o locutor termina seu enunciado para passar a palavra ao outro ou para dar lugar à compreensão responsiva ativa do outro". (p. 294)

ABordagem DE GÊNERo NA ESCOLA

Entre as razões citadas por Meurer (2000) para a importância do estudo do gênero em lingüística aplicada está o fato dele se constituir em uma opção mais atraente do que o ensino da linguagem humana fundamentada na gramática, coesão, modalidades retóricas e coerência na medida em que "responderia de maneira mais adequada a questões relativas aos diferentes usos da linguagem e na interface com o exercício da cidadania"(p.152). Segundo o lingüista, a ineficiência da abordagem tradicional se deve exatamente ao fato de não se preocupar e não dar conta das "situações específicas em que os indivíduos efetivamente utilizam a linguagem como instrumento de interação, reprodução e/ou alteração social".

Entretanto, esse fato parece não ter sido atentado pelos agentes educacionais na orientação do trabalho escolar relativo a textos, tanto do ponto de vista da compreensão quanto da produção, no entender de Antunes (2002) e Bonini (2001).

Antunes recupera o princípio trazido pela Lingüística do Texto de que o ensino da língua materna teria maior relevância se elegesse como objeto de estudo o texto, tanto no plano da recepção como da produção, e a conseqüente mudança de paradigma do professor com relação a suas práticas de sala de aula. Contudo, detalha, sem suporte teórico, esse professor não conseguiu dar "o grande salto", e o texto acabou virando pretexto para o ensino das mesmas tarefas, centradas na gramática normativa. Desse modo, 
conclui, não se atingindo o texto, não se atingiu a língua e nem o discurso, e, conseqüentemente, faltou "compreender que o saber lingüístico, naturalmente desenvolvido pelas pessoas, inclui o saber de seu funcionamento, de seus usos, o que equivale dizer que inclui o saber das condições de produção e recepção de textos". (ANTUNES, 2002, p. 68)

Assim, ao dizer que o texto não tem sido considerado na escola, naturalmente ela aponta que os gêneros textuais/discursivos também não o tem sido. Isso é tão verdadeiro que a seção seguinte de seu artigo tem como título "A relevância dos gêneros textuais como via para o ensino da língua". Já Bonini (2001), ao investigar a abordagem de gênero na escola, afirma que nesta os conteúdos referentes aos gêneros estão dispostos em dois blocos, perfazendo duas tipologias: literária e redacional. Além de salientar que ambas desconsideram a realidade sociointeracional, apresentam critérios de classificação implausíveis e são incompletas - por exemplo, a tipologia redacional se reduz à narração, descrição e dissertação -, o autor aponta que o maior problema desta tipologia é não considerar as esferas sociais onde a ação linguageira se realiza, mas somente as seqüências textuais nas quais os textos se inserem.

\section{IMPORTÂNCIA DO ESTUDO DE GÊNEROS}

Ao assumir, assim, que o ensino da língua tem sido tradicionalmente conduzido de um modo que desestrutura a competência comunicativa do aluno porque centra a reflexão sobre os aspectos formais, retirando a sociedade e a interação da linguagem, Bonini (2001) entende que o estudo do gênero se coloca como uma possibilidade de modificação desse quadro. Explica o raciocínio, lembrando que como a língua reflete os padrões culturais e interacionais da sociedade em que está inserida, pode ser abordada principalmente por meio do conceito de gênero.

Meurer (2000), além da razão mencionada anteriormente - ou seja, alternativa teórica mais atraente do que abordagens textuais restritas às noções de coesão, coerência e modalidades retóricas -, amplia a contribuição do estudo do gênero para a pesquisa. No seu entender, tanto o ensino quanto a pesquisa baseados nos gêneros são importantes porque, em primeiro lugar, não nos comunicamos através de modalidades retóricas nem de textos em geral, mas de gêneros textuais específicos. Além disso, o autor entende que como a própria cultura de um país é caracterizada pelo conjunto de gêneros textuais de seus cidadãos, a investigação e o ensino destes 
são essenciais para a formação de profissionais responsáveis pelo ensino da linguagem no país. ${ }^{2}$

Antunes (2002) entende que uma das possíveis razões para não se ter chegado satisfatoriamente ao nível da textualidade na sala de aula está na redução dos textos aos seus elementos imanentes, não atingindo, assim, o nível das práticas sociais e o nível das práticas discursivas. A partir disso chega à noção de gêneros do texto, detalhando serem estes histórico-culturais, estáveis, e parte do "conhecimento de mundo" das pessoas. Com relação ao ensino, a autora enumera diversas vantagens que poderiam ser obtidas se o ponto fundamental fosse de fato o desenvolvimento de uma competência textual e discursiva. Em linhas gerais, acreditamos ser possível concentrá-las nesses pontos: a apreensão de fatos lingüístico-comunicativos, ao invés do estudo de fatos gramaticais, descontextualizados e virtuais; maiores subsídios para a compreensão e produção de textos; ampliação de perspectivas na compreensão do fenômeno lingüístico, com superação dos parâmetros de "certo" e "errado".

Desse modo, a autora presume que, assumindo-se tais princípios, os textos, tanto em sua dimensão concreta, particular, quanto em sua dimensão típica, enquanto pertencentes a um determinado gênero, passariam a ser objeto de estudo das aulas de língua desde as primeiras séries do Ensino Fundamental. Conseqüentemente, as regras lingüísticas teriam um caráter funcional, e as habilidades propostas contemplariam a variedade de textos relevante para a vida das pessoas. Com isso, então, as dificuldades de produção e recepção de textos diminuiriam, e a língua virtual cederia lugar "à língua que é atuação dos sujeitos falantes, ao lado de tantas outras manifestações culturais com que se vai tecendo a história das pessoas e do universo" (p. 72). A autora especifica que esse ensino via gêneros consistiria na análise de um gênero como ponto nuclear por um tempo determinado, tendo como meta a apreensão de pelo menos oito gêneros diferentes durante o ano letivo, e conclui que, desse modo, se estaria oportunizando um ensino da língua que favorecesse a competência comunicativa dos alunos.

Rojo (2003) não pensa diferente. Ao questionar-se, do ponto de vista aplicado, se o mais produtivo para a melhoria das práticas didáticas seria a transposição da perspectiva da teoria de gênero textual ou a trans-

2 Importante aqui relembrar as três possíveis abordagens da escrita e da palavra na escola sistematizadas por Schnewly e Dolz (1999) - a comunicação é quase inexistente e o gênero torna-se pura forma lingüística cujo objetivo é seu domínio; a escola é tomada como lugar autêntico de comunicação, de produção e de compreensão de textos (e, daí, de gêneros); os gêneros são levados para a escola exatamente como funcionam nas práticas de linguagem de referência, e o ensino visaria ao domínio de instrumentos necessários para funcionar nessas práticas - e buscar, a partir da perspectiva de Meurer, um equilíbrio entre as duas últimas no ambiente escolar. 
posição da teoria de gênero discursivo, a autora opta, calcada em sua experiência tanto na formação de professores como na análise de interações em sala de aula, pela segunda opção. Apesar de entender que os professores são atraídos pela descrição da língua e pelo ensino da gramática, seja pela formação profissional ou pela falta de formação, argumenta que os alunos não precisam ser gramáticos do texto e nem conhecer uma metalinguagem sofisticada. Pelo contrário, o que precisam de fato é ter acesso letrado aos mais diversos textos e poder fazer uma leitura crítica e cidadã deles, e o papel do professor aí seria o de explorar juntamente com eles as características das situações de enunciação presentes nesses textos.

Como dissemos na seção inicial, veremos a seguir até que ponto os professores sujeitos de nossa pesquisa estariam aptos a cumprirem o papel que, segundo Rojo, permitiria chegar a essa leitura crítica e cidadã.

\section{PERCEPÇÃo DE GÊNERO DO PROFESSOR DE LÍNGUA MATERNA}

\section{Sujeitos E METODOLOGiA}

Os sujeitos do estudo foram 26 professores de língua portuguesa do ensino fundamental e/ou médio inscritos em programas de especialização em sua área de atuação de duas universidades gaúchas, uma localizada em Porto Alegre e outra na Grande Porto Alegre, durante o ano letivo de 2004. ${ }^{3}$ Não havia restrição de idade ou ano de graduação, e nem mesmo a necessidade de que os professores estivessem no momento lecionando: a única exigência era a de que tivessem mais de um ano de prática de sala de aula.

Explicou-se aos sujeitos a importância da sua contribuição antes de distribuir o questionário, e as professoras responsáveis pelas turmas disponibilizaram 30 minutos de sua aula para que os alunos o respondessem.

O questionário abria com um cabeçalho, no qual solicitava-se que o respondente colocasse alguns dados pessoais e profissionais: ano de graduação, disciplinas e locais em que lecionava e respectivas séries. Em seguida, eram feitas quatro questões relativas à abordagem de gênero textual na sala de aula, com um espaço, no final, para observações ou comentários sobre o assunto, conforme se segue: 1) Em seu programa, estão contemplados, de alguma forma, os gêneros textuais/discursivos?; 2) O que é gênero 
textual/discursivo para você?; 3) Como você os ensina, geralmente, aos alunos?; 4) A partir dos textos xerocados na folha seguinte, ${ }^{4}$ como você abordaria o conceito de gênero com seus alunos?; 5) Há algum comentário ou observação que você, a partir de sua prática de sala de aula, gostaria de tecer sobre o estudo do gênero na escola?

ANÁLISE dos Dados

GÊnero no Programa de Língua Portuguesa

Frente à primeira questão ("Em seu programa, estão contemplados, de alguma forma, os gêneros textuais?”), de um total de 26 sujeitos, somente dois responderam negativamente, e um ficou em dúvida. Assim, foi possível verificar que a grande maioria tinha consciência de que o programa de suas disciplinas contemplava os gêneros textuais/discursivos, de alguma forma.

$\mathrm{Na}$ verdade, o sujeito que ficou inseguro relatou que "em seus programas há a preocupação de que os alunos tenham contato com diversos tipos de texto e que saibam identificá-los, mas gêneros eu não sei bem se estão", o que é interessante na medida em que esclarece que o programa com o qual trabalha contempla o estudo de gêneros, mesmo que indiretamente, e que ele tem trabalhado com isso, mas sem se dar conta da natureza de seu objeto de trabalho.

É isso também que nos mostra a resposta dos sujeitos que afirmaram entender que os gêneros não eram contemplados em seus programas. Apesar de iniciarem com um não, o complemento de uma delas foi "mas trabalho com a comparação de textos", e de outra foi "mas tenho um projeto de leitura da $5^{\mathrm{a}}$ série. Eles lêem drama, poesia, romances. Os livros são do governo federal, 'Literatura em minha casa'." É simples perceber, pelas complementações, que ao menos indiretamente esses sujeitos trabalham com gêneros, e que, assim, teria sido mais apropriado iniciarem suas respostas com um "sim".

Um outro ponto a se observar aqui é que se percebe a confusão entre tipos e gêneros textuais, como nas afirmações dos sujeitos 03 (sim, há nos conteúdos os gêneros - narração, dissertação e descrição), sujeito 05

4 Um conto de Dalton Trevisan, estruturado no formato de uma carta, e uma pequena notícia da revista Superinteressante sobre cleptomania, com a foto da atriz Wymona Ryder ao lado do texto e o provérbio do escritor inglês Oscar Wild "A melhor maneira de se livrar da tentação é cair nela" em destaque. 
(...gêneros textuais, mais especificamente o dissertativo...) e sujeito 11 (...todos os gêneros são prioritários: narração... gênero dissertativo...).

CONCEITO DE GÊNERo TEXTUAL/DISCURSIVO

A partir da análise das respostas dos professores, apresentadas no Quadro 1 a seguir, pôde-se perceber dois aspectos principais no que tange o conceito de gênero textual/discursivo dos professores, em especial em termos de proximidade/afastamento das idéias colocadas por Bakhtin e assimiladas pelos PCNs: a relação entre gênero e sociedade, fundamental na definição bakhtiniana, não foi retomada pelos sujeitos de modo significativo, o mesmo acontecendo com os elementos que, de acordo com o lingüista russo, devem necessariamente estar presentes na composição do enunciado.

Em relação ao elemento social presente na constituição, circulação e modificação dos gêneros, dos 26 sujeitos, somente um deles (suj. 08) o mencionou explicitamente na sua definição de gênero. Ainda que tenha aparecido uma confusão entre gênero e tipologia textual, ele começa esclarecendo que "qualquer tipo de texto que circule socialmente faz parte de um gênero textual". No entanto, o sujeito 01 também parece contemplar essa relação ao dizer que "o gênero permite compreender tipo de texto, estrutura e caracteriza nossas possibilidades textuais, permitindo as práticas de compreensão e produção".

Além deles, outros dois também conseguiram uma maior especificidade nas suas respostas no que tange a relação sociedade-gênero, comentando, por exemplo, que "a distinção maior entre um gênero e outro reside no objetivo do texto, na finalidade para a qual ele foi produzido e, por conseguinte, reflete-se na linguagem usada" (suj. 07) e, de modo bastante semelhante, que gênero "refere-se à classificação dos diversos tipos de texto, tendo em vista o tipo de linguagem utilizada (literária ou não-literária), intenção de quem escreve..." (suj. 05). Outros já o fizeram de modo mais vago, dizendo, por exemplo, que gênero "é a modalidade em que o texto se manifesta, o estilo que o autor usa para se comunicar" (suj. 06), "são as diferentes maneiras de comunicação textual" (suj. 02), "são as diferentes características que um texto assume por conta da intenção do enunciador" (suj. 11). Já para todos os demais (19 de um total de 26 professores), a relação gênero e contexto social parece não ser vital, dadas as definições como a do sujeito 03, "é um texto com características específicas que se encaixam em uma classificação", a do sujeito 04, que se limita a dizer que 
são todos os tipos de textos, a do sujeito 09, que diz referir-se ao entendimento, leitura e interpretação dos diferentes tipos de texto, a dos sujeitos 10 e 12, que os conceituam por uma divisão entre gêneros literários e não literários, as do sujeito $13,14,19,25$ e 26 , que reduzem os gêneros à tipologia clássica produzida nas escolas: narração, descrição e dissertação.

Se retomarmos a noção de gênero bakhtiniana, veremos que o tema, o estilo e a construção composicional formam um tipo característico de enunciado dentro de um dado espaço de comunicação, sendo por isso que tipos estáveis de enunciados caracterizam gêneros do discurso. Considerando os dados presentes no questionário, e aceitando uma tradução frouxa da noção bakhtiniana de enunciado por texto, podemos constatar que três sujeitos consideraram esses elementos de forma integrada na sua definição de gênero. 0 sujeito 05 faz referência tanto à linguagem utilizada (estilo) quanto à intenção de quem escreve (tema, estilo) e à linguagem (estilo, construção composicional); o sujeito $07 \mathrm{diz}$ que a distinção maior entre um gênero e outro reside no objetivo do texto (tema), finalidade para a qual foi produzido (construção composicional), que, conseqüentemente, reflete-se na linguagem usada (estilo), e o sujeito 08 afirma que o gênero se define, sobretudo, pelas marcas discursivas (construção composicional) e lingüísticas (tema, estilo) do texto. Em algumas respostas, apenas um desses componentes é lembrado - como, por exemplo, na do sujeito 06, que define gênero como "o estilo que o autor usa para se comunicar", e na do sujeito 11 , que atribui as diferentes características que o texto assume à intenção do enunciador. Em outras - por exemplo, respostas dos sujeitos 19, 20, 24 -, apesar de ser usada a expressão geral "forma de texto", o próprio exemplo dado pelos sujeitos para explicar diferentes "gêneros" (invariavelmente, narração, descrição e dissertação) mostra que o sentido dado por eles ao termo não cobre os três componentes indissociáveis do enunciado para Bakhtin.

Por último, cabe ainda apontar que nove sujeitos, um pouco mais do que um terço do total, confundiram a noção de gênero com a de tipologia

Quadro 1: Respostas compatíveis, aproximadas e incompatíveis com a noção bakhtiniana de gênero

\section{Respostas compatíveis}

- Gêneros textuais, para mim, são as várias possibilidades de texto e suas "marcas". o gênero permite compreender tipo de texto; estrutura e caracteriza nossas possibilidades textuais, permitindo as práticas de compreensão e produção. (Suj. 01) 


\section{Respostas aproximadas}

- Qualquer tipo de texto que circule socialmente faz parte de um gênero textual. o gênero será definido, sobretudo, pelas marcas discursivas e lingüísticas do texto. Podemos falar em gênero narrativo, argumentativo, expositivo, instrutivo, entre outros. (Suj. 08)

- Ao meu ver, a distinção maior entre um gênero e outro reside no objetivo do texto, na finalidade para a qual ele foi produzido e, por conseguinte, reflete-se na linguagem usada, isto é, no tratamento dispensado a ela. (Suj. 07)

- Refere-se à classificação dos diversos tipos de texto, tendo em vista o tipo de linguagem utilizada (literária ou não-literária), intenções de quem escreve, características específicas de cada gênero. Gênero textual parece-me bem mais abrangente do que gêneros literários, pois envolve além dos tradicionais (épico, narrativo, dramático e lírico), textos não-literários, como os dissertativos (editoriais, reportagens, textos científicos, ensaios...) (Suj. 05)

- É a modalidade em que o texto se manifesta, o estilo que o autor usa para se comunicar (escrever). (Suj. 06)

- São as diferentes maneiras de comunicação textual.(Suj. 02)

- São as diferentes características que um texto assume devido, ou por conta, da intenção do enunciador. Os gêneros textuais estão ligados às funções da linguagem. (Suj. 11)

\section{Respostas incompatíveis}

- É um texto com características específicas que se encaixam em uma classificação. (Suj. 03)

- Todos os tipos de texto: narrativo, descritivo, poético, jornalístico, informativos, literários, etc. (Suj. 04)

- A noção de gênero textual refere-se ao entendimento, à leitura e à interpretação dos tipos elencados acima (ou seja, estórias, contos de fada, contos, crônicas, poemas, reportagens, publicidades.) (Suj. 09)

- Assim, sem pesquisar, acho que eu diria que os gêneros seriam literários e nãoliterários. E que nestes teríamos os tipos de texto: editorial, publicitário, propaganda, etc. (Suj. 10)

- Entendo como literários e não-literários, os quais seriam subdivididos em tipos de textos. (Suj. 12)

- Tipos de textos, forma de como escrevemos, quer seja narrativo, descritivo ou dissertativo. (Suj. 13)

- São as formas de textos, narrativo, descritivo e dissertativo. (Suj. 14)

- É o tipo de texto apresentado - poema, romance, conto, crônica. (descritivo, narrativo, informativo, para mim também é gênero, acho) (Suj. 15) 
- São os diferentes tipos de texto, como poesia, conto, crônica, etc. (Suj. 16)

- São os textos diversificados, onde podemos trabalhar a interpretação. (Suj. 17)

- São tipos de textos: poema, romance, nota fiscal, conta de luz (informativo) (Suj. 18)

- São as diversas formas de como o texto se apresenta (narrativo, descritivo e dissertativo) (Suj. 19)

- É a forma e o conteúdo que juntos formam um todo, chamado texto. Ou o conteúdo de um texto expresso de uma certa forma. (Suj. 20)

- Gênero textual diz respeito às diversas formas de apresentação do texto. (Suj.

21)

- É a forma de como um texto pode ser escrito. (Suj. 22)

- Gênero textual é como o texto se apresenta, de que forma, de que maneira podemos verificar características e classificá-lo como um todo. (Suj. 23)

- Diferentes tipos de texto escrito de formas diferentes, usando uma linguagem diferente. Exemplo: narração, descrição, argumentativo, etc. (Suj. 24)

- É o tipo de texto abordado (em sala), ou seja, se é narrativo, descritivo, dissertativo, etc. (Suj. 25)

- As diferentes tipologias do texto encontradas: dissertativo, descritivo, narrativo. Entre as formas de conto, crônica, poesia, histórias em quadrinhos, ícones... (Suj. 26)

textual, sendo que a mencionada era mais comumente a reduzida a três categorias, de acordo com a praticada por muito tempo nas escolas, e outros nove fizeram uma equivalência entre tipos de textos e gêneros ao pensarem na sua concepção de gênero textual - "gêneros são tipos de textos...".

ABORDAGEM DE GÊNERO

Do total de sujeitos, quatro afirmaram não lidar com o conceito de gênero textual em suas práticas de sala de aula. o primeiro (suj. 12) explicou que seu objetivo não era fazer a distinção entre texto não-literário e literário (a partir de sua idéia de que os gêneros textuais/discursivos se distinguem, primariamente, por esse critério), o segundo (suj. 10) concluiu que sempre havia trabalhado com uma noção de tipologias textuais, e não de gênero, pois como não fazia parte do programa, era "a título de curiosidade", e os dois últimos (suj. 09 e suj. 18) encontraram justificativa nas séries que lecionavam. Um deles possuía um grupo de alunos de $5^{\mathrm{a}}$ série 
em que trabalhava somente com leitura, mais especificamente literatura infanto-juvenil, "mais livre, nada teórico", e o outro, que atendia a uma $4^{\mathrm{a}}$ série, argumentou que nesse nível "não seria relevante explorá-los." 5

O fato significativo é que um olhar um pouco mais detalhado nos permite identificar pelo menos mais seis sujeitos que, a exemplo do sujeito 10, têm trabalhado somente com uma noção de tipologia textual. Por exemplo, o sujeito 03 diz fazer, após a leitura e apresentação das características do texto (sem defini-las, no entanto), um levantamento, juntamente com os alunos, "das ocorrências de passagens dissertativas, narrativas ou descritivas", propondo, "a partir dos modelos, a produção em que apareçam as características predominantes". Sua resposta, desse modo, estaria adequada se a pergunta fosse sobre a abordagem de seqüências/ tipologias textuais, mas não contempla os gêneros. Com uma lógica parecida, o sujeito 11 , ao enfatizar os diferentes "gêneros" abordados de acordo com as séries em sua escola, esclarece que "na $8^{a}$ série parte-se para a dissertação, enfatizando a postura dos alunos frente à problemática de cada texto", e o sujeito 14 comenta que sua prática de ensino de gêneros baseia-se em exemplos de diferentes gêneros, e em parênteses ilustra alguns desses: narrativo, descritivo e dissertativo. Já os sujeitos 13, 24 e 25, apesar de responderem de modo bastante vago ("trabalhando com textos variados", "através de textos", "mostrando textos e suas características"), também deixam claro, ao confundirem gênero com tipologia textual na resposta à questão anterior, que seu trabalho tem como foco a classificação de textos, e não seu entendimento enquanto manifestação lingüística do discurso, "produto da atividade discursiva oral ou escrita que forma um todo significativo, qualquer que seja sua extensão" (PCNs, 1998, p. 21). O mesmo pôde-se concluir do sujeito 19 , com base na sua resposta à questão quatro ("o texto 1 eu abordaria como texto descritivo/narrativo e o texto 2 como dissertativo").

Além disso, algumas respostas pareciam não ser endereçadas à pergunta feita, o que acabou por invalidá-las, como as do sujeito 4 ("procuro trabalhar textos com temas que interessem a eles, pois a adolescência é rica em criatividade e conflitos"), 15 ("”aulas expositivas, trabalhos em grupos, discussões em aula, jogos..."), 21 ("através de textos, tanto na produção quanto na identificação") e 26 (" procuro trabalhar mais a leitura e a escrita através da reescrita, pelos alunos, dos textos e a recriação das ilustrações, sabendo o ponto de vista dos alunos"). Entre essas respostas pouco coerentes, há uma (suj. 16) que merece citação em separado por ilustrar com bastante clareza a utilização do texto em sala de aula como pretexto e não como objeto de estudo em si, e, decorrente disso, o ambiente virtual, em 
oposto a real, de ensino de língua (e somente ensino, já que é difícil acreditar que a aprendizagem, em tal contexto, acontecerá):

Utilizando os diversos tipos para trabalhar aspectos gramaticais do texto e verificar o grau de compreensão do aluno. Posteriormente, era apresentada uma proposta de redação para trabalhar a estrutura, o tema, ou ambos.

Das dez restantes, todos responderam que costumam ensinar gêneros textuais/discursivos aos alunos através da análise de textos variados, uns de forma mais vaga, outros de forma mais detalhada. ${ }^{6}$

No entanto, um pouco dessa vaguidade foi diminuída pelos dados obtidos através da questão seguinte, na qual solicitava-se que os sujeitos dissessem como abordariam o conceito de gênero textual/discursivo com seus alunos a partir dos dois textos anexos ao questionário, um conto de Dalton Trevisan e uma notícia da revista Superinteressante. Com base nessas respostas, foi possível notar que quatro desses dez professores, no contexto de seu trabalho com gênero, focalizam mais aspectos lingüísticos do que discursivos. ${ }^{7}$ Como suporte a essa afirmação, cabe a argumentação de que as condições de produção dos textos não aparecem freqüentemente como itens de análise nas respostas dos sujeitos 06, 07, 08 e 17. Por exemplo, os sujeitos 06 e 07 afirmam que levariam o aluno a observar "como" o autor aborda o assunto, "como" ele se comunica com o leitor, "como" as coisas são ditas, mas em nenhum momento comentam sobre a importância de o aluno refletir sobre o por quê disso. Os sujeitos 08 e 17 decidem que trabalhariam as marcas "lingüísticas" do texto, distinguindo as que são próprias da linguagem literária e as que não são, sendo que o primeiro abordaria ainda o "grau de objetividade dos textos, bem como os veículos portadores de textos". Desconsiderando-se as respostas do sujeito 20 ("o texto 1 é literário porque provém da criação do autor e o texto 2 é informativo porque atém-se a um fato real.”) e do sujeito 22 , transcrita a seguir,

6 De acordo com o que escrevem, por exemplo, o sujeito 2 ("selecionando textos diversos, principalmente de jornais (mais acessíveis), e explorando as linguagens de cada um") e o sujeito 17 ("trabalho o texto em si através de poesias, crônicas textos literários, não-literários, fazendo uma análise. Muitas vezes, trazendo a realidade social para aquele momento"), torna-se difícil precisar a abordagem utilizada pelo professor.

14 A partir da distinção estabelecida por Rojo (2003), poderia se dizer que a vertente utilizada por eles está embasada nas teorias de gênero textual e não de gênero discursivo.

A partir da distinção estabelecida por Rojo (2003), poderia se dizer que a vertente utilizada por eles esté embasada nas teorias de gênero textual e não de gênero discursivo. 
Texto 1 - Diferenças: uso da $1^{\text {a }}$ pessoa; características: situado no tempo e no espaço; estrutura: prosa.

Texto 2 - Texto na $3^{\text {a }}$ pessoa do singular; Características: comentar um fato; introdução, desenvolvimento e conclusão; estrutura: notícia, jornal, foto, informação.

por confundirem mais do que esclarecerem, ficamos então somente com quatro sujeitos $(01,02,05$ e 23$)$ que, com base nas suas respostas às questões, possuem uma concepção de gênero herdada da tradição bakhtiniana e, assim, em conformidade com a proposta delineada pelos PCNs para o ensino da língua portuguesa. O fato de se preocuparem em analisar os motivos pelos quais os textos são escritos (suj. 02), a finalidade do texto e a relação tempo e espaço a partir do conhecimento do aluno (suj. 01) e de formularem questões a fim de que o aluno consiga perceber por que determinado texto pertence a um gênero e não a outro (suj. 05 e 23) evidencia isso.

COMENTÁRIOS SOBRE O ESTUDO DE GÊNERO NA ESCOLA

Quinze sujeitos, de um total de vinte e seis, fizeram comentários sobre a abordagem de gênero nas escolas a partir de sua prática de sala de aula. Entre esses, somente o comentário do sujeito 04 não se ateve mais diretamente ao tópico, mas optamos por iniciar com ele - " a escola incentiva muito pouco a leitura; ela muitas vezes é hipócrita. Pede aos alunos que leiam, mas os professores têm pouco interesse e desempenho para realizar atividades com texto" - porque acreditamos que se de fato essa é uma realidade em algumas escolas, é natural que o estudo do gênero acabe não recebendo a devida atenção.

E que ele não está recebendo a devida atenção nas escolas é a conclusão a que se chega ao ler oito das outras quatorze observações. As mais explícitas a esse respeito foram as dos sujeitos 08, 10 e 12 . Enquanto o primeiro disse sentir que o estudo dos gêneros é relativamente novo, sua prática em sala de aula é "acanhada" e há escassez de materiais e informações para os professores realizarem um trabalho de qualidade sobre o assunto, para o segundo o conceito de gênero fica mesmo em segundo plano, afirmando não lembrar-se de o ter estudado durante sua graduação. Finalmente, o sujeito 12 relata que não é comum ver uma discussão sobre gênero entre os professores de língua portuguesa, mas somente entre os de literatura. Confirma dizendo nunca haver discutido a noção com seus colegas 
em seus onze anos de prática de sala de aula como professora de língua portuguesa. ${ }^{8}$

Ao refletirem sobre diferentes aspectos de sua prática relacionados ao tratamento de gêneros textuais/discursivos, outros sujeitos deixaram transparecer questões mais pontuais, as quais, de qualquer modo, também apontam para uma incompletude do ensino de língua materna via gêneros. Por exemplo, o sujeito 19 conclui que o professor deveria "levar o aluno a perceber as características que se diferenciam a cada tipo de texto, e não apenas conceituá-los", e o sujeito 25, diversamente, entende que "o gênero é trabalhado, de alguma forma, em sala de aula, não há uma preocupação em denominar.” No entanto, se lembrarmos que ambos exemplificam gênero através da tipologia escolar, clássica narração, descrição, dissertação, perceberemos quanto mais problemáticas tornam-se suas observações.

Nesse contexto, são pertinentes os comentários dos sujeitos 20 e 21 , o primeiro ao afirmar que o poema deveria ser mais trabalhado no Ensino Fundamental, mas sem explicar por quê, e o segundo pelo critério de seleção do gênero dramático como "o melhor de todos": os alunos podem criar, representar e vivenciar o gênero com representações próprias. Mesmo sendo um parâmetro possível, desperta a atenção a desconexão com os aspectos sócio-históricos relativos ao uso da linguagem, ou, dito de outro modo, com as práticas discursivas enquanto modo de interação do homem pela linguagem.

A opinião do sujeito 07 também se enquadra aqui. No seu entender, o que há de negativo no trabalho com gênero nas escolas são as "misturas" de textos que são apresentadas aos alunos; o aluno deveria aprender primeiramente um gênero, e depois então iniciar com outro. $O$ dado relevante aqui é que, nos parece, essa proposta de metodologia vai na contramão das palavras de Bonini (2001) quando afirma acreditar que o estudo de gênero se colocaria como uma possibilidade de modificar o estudo tradicional da língua, que acaba por desestruturar a competência comunicativa do aluno ao centrar a reflexão sobre os aspectos formais, retirando a sociedade e a interação da linguagem. Parece-nos que, pela proposta acima, mesmo o estudo do gênero em sala de aula, se não conduzido com cuidado, pode no final tornar-se meramente uma reflexão sobre seus aspectos formais, $o$ que traria pouca contribuição no sentido de integrar sociedade, interação e linguagem. Propor que o aluno tenha contato com um único gênero textual em sala de aula, mesmo que por um período curto de tempo, é desvincular

8 O que vai ao encontro dos comentários de dois professores que ensinam somente língua portuguesa, os sujeitos 15 ("na verdade, pouco trabalho o conceito gênero literário, acho que nem sei o que é") e o 18 ("faz 12 anos que me formei na graduação e nunca mais trabalhei com o gênero literário, teoria”). 
o aprendizado da língua do aprendizado do uso da língua. Mesmo que durante a aula de língua portuguesa isso seja possível, nas outras disciplinas e fora da escola esse aluno estará tendo contato com vários gêneros ao mesmo tempo, e não conseguimos ver maneira melhor de lidar com toda essa diversidade do que fazer com que o aluno tome conhecimento dela o quanto antes possível.

Dos outros seis comentários, dois (suj. 15 e 18) restringiram-se a lembrar que não abordam gêneros literários em suas aulas de língua portuguesa, outros dois (suj.16 e 17) atribuíram a dificuldade do trabalho com textos em sala de aula à falta de interesse e "deficiências" dos alunos, e os últimos dois (suj. 06 e 26) expressaram opiniões mais gerais. Enquanto o sujeito 06 enfatizou a importância de explorar "o dia-a-dia e o que é fácil de conseguir: revistas, jornais, rótulos, propagandas de lojas e supermercado", o sujeito 26 deixou evidente uma compreensão da relação gênero discursivo-ensino que não poderia estar melhor sintonizada com as reflexões teóricas recentes. Assim, encerramos o relato de nossos dados positivamente com ela:

Acredito que o estudo dos gêneros e, conseqüentemente, o trabalho efetivo em sala de aula, dá uma visão mais ampla das várias maneiras de como podemos nos expressar e escrever, o que amplia o universo da compreensão e leitura das várias realidades que nos cercam. Tudo isso contribui para um aluno, ser humano, mais crítico e agente no meio em que vive.

\section{CONSIDERAÇõES FINAIS}

De modo geral, a análise das contribuições dos 26 professores nos permite dizer que sua concepção de gênero textual/discursivo não está em conformidade com a advinda da teoria bakhtiniana. Ainda que os elementos constituintes do gênero apareçam nas respostas de alguns sujeitos, a essência dele não é contemplada.

Essa essência, que é a relação entre os gêneros e a sociedade na qual eles ocorrem (ou, em outros termos, o contexto sócio-histórico), foi lembrada por apenas um dos vinte e seis professores questionados. Como vimos, embora outros tenham se aproximado mais dessa relação ao utilizarem palavras como comunicação, ou mesmo ao fazerem referência à intenção do autor e ao objetivo de texto, não chegaram a fazê-la de modo direto. 
Além disso, e apesar do número reduzido de informantes, pudemos analisar alguns dados que, se tomados a partir de estudos teóricos sobre o ensino de gênero nas escolas, nos levarão, necessariamente, à reflexão. Entre eles, o dos dois professores de $4^{\mathrm{a}}$ e de $5^{\mathrm{a}}$ séries que revelaram não ser importante explorar gêneros nessa fase escolar, o dos sete professores de ensino fundamental e médio que reduziram a variedade de gêneros a tipologias e seqüências textuais, o dos dois professores que equipararam gênero textual à leitura e compreensão de textos, o dos também dois professores que trabalham com gêneros sem saber que o fazem, e o do professor que entende que a noção de gênero deve ser trabalhada na aula de literatura, e não na de língua portuguesa.

$\mathrm{Na}$ verdade, como já visto anteriormente, pela análise conjunta das respostas foi possível perceber que apenas quatro professores, de um total de 26 - ou seja, $15 \%$ - parecem trabalhar com gêneros discursivos em sala de aula a partir do parâmetro esboçado pelo Ministério da Educação há quase uma década.

Desse modo, retomando as questões norteadoras, enquanto nossa análise permite uma resposta afirmativa à primeira - os professores têm consciência de que seu componente curricular contempla o estudo de gêneros? -, o mesmo não acontece com a segunda, relacionada à conformidade da noção de gênero esboçada nos PCNs para a língua portuguesa com a presente no professor de português. Do mesmo modo, a última questão, sobre o tipo de abordagem utilizada pelo professor para ensinar gêneros discursivos aos alunos, mostrou que, de modo geral, acontece uma confusão entre tipologia e gênero textual. Assim, não podemos dizer que o professor conhece e trabalha somente com essas três tipologias, mas a impressão que tivemos é que ele, em muitas situações, não tem bem claro o que diferencia as noções de tipologia de gênero textual/discursivo. De qualquer maneira e em termos gerais, não nos parece que, a partir do que ele relatou nas respostas, seu conhecimento lhe permita uma exploração significativa dos gêneros discursivos.

Resgatando a justificativa para nosso trabalho, ela residia no fato de haver um número razoável de estudos sobre a abordagem de gêneros em livros didáticos, alguns desses sintetizados aqui, mas não sobre a percepção e abordagem de gêneros pelo professor. Nosso argumento era então o de que, como essas análises estavam mostrando que o material didático não tratava adequadamente o conceito de gêneros textuais/discursivos, seria necessário saber se o professor, por sua vez, estaria apto a preencher essas "lacunas teóricas".

Biasi-Rodrigues (2002), ao examinar a noção de gênero em livros didáticos, comenta, frente a uma seção na qual uma certidão de casamento é reproduzida, que "a estrutura do documento e as condições de produção" necessitam de "uma boa orientação do professor para esse gênero textual", 
o mesmo acontecendo com o gênero convite, que aparece em seguida. Infelizmente, a conclusão à qual chegamos, com base na nossa amostra, é que a maioria dos professores não teria um conhecimento de gênero discursivo suficiente para responder às possíveis incongruências encontradas em muitos materiais didáticos.

No entanto, temos que considerar que essas observações são todas feitas a partir de um número bastante reduzido de informantes, e é possível que, frente a uma outra amostra, elas tivessem sido diferentes. ${ }^{9}$ Como entendemos que conhecer o quanto o professor de ensino fundamental e/ou médio sabe sobre gêneros textuais/discursivos é a questão mais relevante com relação à formação de alunos-leitores críticos e cidadãos, a realização de outros estudos com o mesmo objetivo do que o nosso, envolvendo grupos de professores das mais variadas formações e localidades brasileiras, nos parece bem-vinda para que se possa traçar um panorama mais apurado tanto da noção teórica de gênero do professor de língua materna como, conseqüentemente, do reflexo desta na sua prática. Já que cabe ao professor fazer a ponte entre o material didático de língua portuguesa - ou seja, todo e qualquer texto - e o aluno, e já que se espera que essa ponte leve ao domínio das práticas de linguagem, o primeiro passo é saber se ele tem feito isso a partir da noção de gênero discursivo. Se não for o caso - e, de acordo com o nosso estudo, parece não ser, pelo menos para a grande maioria dos nossos sujeitos -, alternativas precisam ser pensadas, já que trabalhar com textos e desconsiderar as particularidades do gênero "leva ao formalismo e à abstração, desvirtua a historicidade do estudo, enfraquece o vínculo entre a língua e a vida" (BAKHTIN, p. 282). Como sabemos, esse, de modo algum, é um aprendizado significativo.

\section{RESUMO}

Considerando-se tanto (i) a importância da noção de gênero discursivo para a prática de ensino de língua materna como (ii) o resultado de estudos que mostram que essa noção não é suficientemente explorada na maioria dos materiais didáticos, essa pesquisa, de caráter qualitativo, teve como objetivo investigar a percepção desse conceito pelo professor de língua portuguesa de ensino fundamental e médio. De modo geral, os

9 Há uma variável, contudo, que torna nossa amostra, ainda que reduzida, especial para o nosso objetivo: todos estavam freqüentando um curso de especialização em sua área de conhecimento, o que deveria, a princípio, ter facilitado o esclarecimento de questões teóricas relacionadas diretamente com sua prática de ensino, como, aqui, a de gênero textual/discursivo. Como vimos, essa variável parece não ter tido influência significativa em um âmbito geral. 
dados desenham um professor sem amparo teórico para cobrir a lacuna deixada pelo material didático.

Palavras-chave: Gênero discursivo; Bakhtin; ensino de língua portuguesa.

\begin{abstract}
Taking into consideration both the (i) importance of the notion of discourse genre to the teaching of a first language and the (ii) findings from studies showing that such a notion is faultily approached in most textbooks, the aim of this qualitative study was to investigate how teachers of Portuguese understand the concept. In general, data point to a teacher with no theoretical support to bridge the gap left by textbooks.

Key-words: Discourse genre; Bakhtin; teaching of Portuguese as a first language.
\end{abstract}

\title{
REFERÊNCIAS
}

ANTUNES, Irlandé Costa. Língua, gêneros textuais e ensino: considerações teóricas e implicações pedagógicas. Perspectiva, Florianópolis, v. 20, n. 1, p. 65-76, jan./jun. 2002.

BAKHTIN, Mikhail. Estética da criação verbal. São Paulo: Martins Fontes, 1992.

BIASI-RODRIGUES, Bernardete. A diversidade de gêneros textuais nos livros didáticos: um novo modismo? Perspectiva, Florianópolis, v. 20, n. 1, p. 49-64, jan./jun. 2002.

BONINI, Adair. Ensino de gêneros textuais: a questão das escolhas teóricas e metodológicas. Trabalhos em Lingüística Aplicada, n. 37, p. 7-23, 2001.

BRASIL/SEF/MEC. Parâmetros Curriculares Nacionais - Língua Portuguesa - $1^{\circ}$ e $2^{\circ}$ ciclos do Ensino Fundamental. Brasília: SEF/MEC, 1997.

Parâmetros Curriculares Nacionais - Língua Portuguesa $-5^{\mathrm{a}}$ a $8^{\mathrm{a}}$ séries do Ensino Fundamental, vd. 2. Brasília: SEF/MEC, 1998.

MEURER, José Luiz. O conhecimento de gêneros textuais e a formação do profissional da linguagem. In: FORTKAMP, Mailce Borges Mota; TOMITCH, Lêda Maria Braga (Orgs.). Aspectos da lingüística aplicada. Florianópolis: Insular, 2000.

ROJO, Roxane. Gêneros do discurso e gêneros textuais: questões teóricas e aplicadas. In: MEURER, J. L. et al. (Orgs.). Gêneros textuais/discursivos em diferentes perspectivas. Florianópolis: UFSC, 2003. No prelo.

. Palavra e gênero em práticas alfabetizadoras. Intercâmbio, v. 12. São Paulo: LAEL/ PUC-SP, p. 165-173, 2003a.

SCHNEUWLY, Bernard; DOLZ, Joaquim. Os gêneros escolares. Das práticas de linguagem aos objetivos de ensino. Revista Brasileira de Educação, n. 11, Rio de Janeiro: Anped, 1999. Tradução de Glaís Sales Cordeiro. 